\title{
Effect of annealing on phase transition in poly(vinylidene fluoride) films prepared using polar solvent
}

\author{
S SATAPATHY*, SANTOSH PAWAR ${ }^{\dagger}$, P K GUPTA and K B R VARMA ${ }^{\dagger \dagger}$ \\ Laser Materials Development and Devices Division, Raja Ramanna Centre for Advanced Technology, \\ Indore 452 013, India \\ ${ }^{\dagger}$ Department of Applied Physics, SGSITS, Indore 452 003, India \\ ${ }^{\dagger \dagger}$ Materials Research Centre, Indian Institute of Science, Bangalore 560 012, India
}

MS received 7 April 2010; revised 6 May 2010

\begin{abstract}
The $\gamma$-phase poly (vinylidene fluoride) (PVDF) films are usually prepared using dimethyl sulfoxide (DMSO) solvent, regardless of preparation temperature. Here we report the crystallization of both $\alpha$ and $\gamma$-phase PVDF films by varying preparation temperature using DMSO solvent. The $\gamma$-phase PVDF films were annealed at $70,90,110,130$ and $160^{\circ} \mathrm{C}$ for five hours. The changes in the phase contents in the PVDF at different annealing conditions have been described. When thin films were annealed at $90^{\circ} \mathrm{C}$ for $5 \mathrm{~h}$, maximum percentage of $\beta$-phase appears in PVDF thin films. The $\gamma$-phase PVDF films completely converted to $\alpha$-phase when they were annealed at $160^{\circ} \mathrm{C}$ for $5 \mathrm{~h}$. From X-ray diffraction (XRD), Fourier transform infrared spectrum (FTIR), differential scanning calorimetry (DSC) and Raman studies, it is confirmed that the PVDF thin films, cast from solution and annealed at $90^{\circ} \mathrm{C}$ for $5 \mathrm{~h}$, have maximum percentage of $\beta$-phase. The $\beta$-phase PVDF shows a remnant polarization of $4.9 \mu \mathrm{C} / \mathrm{cm}^{2}$ at $1400 \mathrm{kV} / \mathrm{cm}$ at $1 \mathrm{~Hz}$.
\end{abstract}

Keywords. PVDF; phase transition; XRD; FTIR; Raman-spectra; DSC; hysteresis.

\section{Introduction}

PVDF, a semi-crystalline polymer exists in four different forms. The $\beta$-phase is the desirable phase due to its ferroelectric characteristic. Phase I ( $\beta$-phase) has a planer TTTT (all trans) zigzag chain conformation which has space group $C m 2 m$ (orthorhombic, $a=8.58 \AA, b=4.91 \AA$, $c=2.56 \AA$ ) (Lando et al 1966; Hasegawa et al 1972a). The $\alpha$-form, phase II (monoclinic, $P 2_{1} / c ; a=4.96 \AA, b=$ 9.64 $\left.\AA, c=4.62 \AA, \beta=90^{\circ}\right)$ has a chain conformation which is approximately TGTG (trans- gauche-transgauche) (Lando et al 1966; Hasegawa et al 1972b). Phase III ( $\gamma$-phase) has a chain conformation which is approximately TTTGTTTG', with the space group being $C 2 \mathrm{~cm}$ (Weinhold et al 1980). Application of high electric field to phase II ( $\alpha$-form), may cause $180^{\circ}$ rotation of alternate chains leading to a polar, monoclinic form IV crystal ( $\delta$-phase) (Davis et al 1978; Dasgupta and Doughty 1978; Newman et al 1979). In $\beta$-phase the dipole moments of the two $\mathrm{F}-\mathrm{C}$ and two $\mathrm{C}-\mathrm{H}$ bonds add up in such a way that the monomer gets an effective dipole moment in the direction perpendicular to the carbon backbone. So the $\beta$ phase has the largest spontaneous polarization per unit cell and thus exhibits the most superior ferroelectric and piezoelectric properties (Chen et al 2007). It is important

\footnotetext{
*Author for correspondence (srinu73@rrcat.gov.in)
}

to maximize $\beta$-phase in PVDF film. Different phases exist in PVDF depending on synthesis conditions like solvent, melt temperature, method of casting, stretching of thin films and annealing conditions. Buonomenna et al (2007) show the effect of casting, solvent and coagulation conditions on the crystalline structure of PVDF.

PVDF films derived from DMF (dimethylformamide) polar solvent have been reported in literature to have a polar $\beta$-phase. But the $\beta$-phase is only stable at low temperatures (less than $50^{\circ} \mathrm{C}$ ), at which the films are too porous for electrical applications (He and Yao 2006; Chen et al 2007). Dense $\beta$-phase is dominant in PVDF thin films which have been obtained by spin coating PVDF/ DMF solution with addition of $\mathrm{Mg}\left(\mathrm{NO}_{3}\right)_{2} \cdot 6 \mathrm{H}_{2} \mathrm{O}$ and dried at $100^{\circ} \mathrm{C}$ (He and Yao 2006; Chen et al 2007). Only below a certain temperature the deformation of the $\alpha$-phase results in transformation to the $\beta$-phase (polar) form.

Mohammadi et al (2007) have shown the effect of stretch rate on conversion of $\alpha$-phase to $\beta$-phase (Sajkiewicz et al 1999). Maximum $\beta$-phase content was obtained at $90^{\circ} \mathrm{C}$ during stretching (Salimi and Yousefi 2003). The abrupt increase in orientation of $\beta$ crystallites and maximum content of the $\beta$-form occur closely above the temperature of $\alpha_{\mathrm{c}}$ relaxation temperature (between $70-87^{\circ} \mathrm{C}$ ) (Salimi and Yousefi 2003).

The $\gamma$-phase has been produced by either casting from DMSO or dimethylformamide solution regardless of preparation temperature (Cortili and Zerbi 1967; Okuda et al 
1967; Gal'Perin et al 1970; Hasegawa et al 1972a; Park et al 2005). The $\gamma$-phase can be produced by crystallizing from melt under high pressures (Welch and Miller 1976) and can also be produced as a result of an atmospheric pressure annealing induced transformation from the $\alpha$-phase (Prest Jr and Luca 1975). The percentage of $\gamma$-phase increases when $\alpha$-phase thin film annealed at $158^{\circ} \mathrm{C}$ for $95 \mathrm{~h}$ (Prest Jr and Luca 1978). When $\beta$-phase thin film is annealed at $181^{\circ} \mathrm{C}$ at heating rate $0.31 \mathrm{~K} / \mathrm{min}$, then large percentage of $\beta$-crystallite is transformed to $\gamma$-phase (Prest Jr and Luca 1978). There is no clear report on the transformation of $\gamma$-phase to $\beta$-phase in PVDF.

In this paper we report the crystallization of $\alpha$ and $\gamma$-phase PVDF using DMSO solvent at preparation temperatures $50^{\circ} \mathrm{C}$ and $90^{\circ} \mathrm{C}$ respectively contradicting earlier reports. We choose preparation temperatures above $\alpha$ phase relaxation temperature $\left(90^{\circ} \mathrm{C}\right)$ and below $\alpha$-phase relaxation temperature $\left(50^{\circ} \mathrm{C}\right)$ because above and below $\alpha$-phase relaxation temperature different phases exist in the PVDF films.

The conversion of $\gamma$-phase to $\beta$-phase (which is still unclear from studies) and $\gamma$-phase to $\alpha$-phase at different annealing conditions has also been reported. We show that the $\alpha, \beta$ and $\gamma$-phase PVDF films can be produced using same polar solvent. Strong correlations have been observed among the characterization results.

\section{Experimental}

PVDF thin films were prepared from DMSO solvent at two different temperatures $\left(90^{\circ} \mathrm{C}\right.$ and $\left.50^{\circ} \mathrm{C}\right)$. The granular PVDF (Sigma Aldrich) was dissolved in the solvent DMSO ( $15 \mathrm{wt} \%$ concentration). In the first case the temperature of the solution was increased to $90^{\circ} \mathrm{C}$ for complete dissolution of the polymer. The solution was cast uniformly on the glass substrate at room temperature. The films were kept at room temperature for one hour and then dried at $60^{\circ} \mathrm{C}$. Free standing thin films were obtained after immersing in water. The thickness of PVDF films is $30 \mu \mathrm{m}$.

In the second case, the PVDF (15 wt\%) dissolved completely at $50^{\circ} \mathrm{C}$ and was cast at room temperature on glass plates. The thin films were kept at room temperature for one hour and then dried at $60^{\circ} \mathrm{C}$.

The films (which were cast at room temperature from solution at $90^{\circ} \mathrm{C}$ ) were annealed at $70,90,110,130$ and $160^{\circ} \mathrm{C}$ for $5 \mathrm{~h}$. In each annealing condition PVDF films were heated at a heating rate $2^{\circ} \mathrm{C} / \mathrm{min}$ to reach annealing temperature and these films were cooled to room temperature at the same rate. To study the presence of different phases these PVDF films were characterized at room temperature. Phases of thin films were analyzed by XRD, using $\mathrm{CuK} \alpha$ radiation, with the generator working at $40 \mathrm{kV}$ and $40 \mathrm{~mA}$. FTIR spectra of the films were recorded by a Perkin Elmer Spectrometer over a range of
$400-2000 \mathrm{~cm}^{-1}$. The Raman measurements on PVDF films were carried out using $632.8 \mathrm{~nm}$ excitation source using LABRAM-HR spectrometer equipped with a peltier cooled CCD detector. The melting behaviour of PVDF films (annealed at different temperatures) were investigated by DSC at a heating rate of $5^{\circ} \mathrm{C} / \mathrm{min}$. The melting point, crystallization and phase transition of $\alpha-\beta$ - and $\gamma$-phases of PVDF were observed from DSC curves during heating cycle of DSC. Polarization (hysteresis loop measurement) measurements of PVDF thin films were performed using RT66A radiant ferroelectric loop tracer.

\section{Results and discussion}

\subsection{Crystallization of $\alpha$ and $\gamma$-phase PVDF films using DMSO solvent}

Figure 1 shows the X-ray diffraction pattern of PVDF thin films, prepared at $90^{\circ} \mathrm{C}$ and $50^{\circ} \mathrm{C}$ using DMSO solvent. The peak at $2 \theta=20 \cdot 3(101)$ in XRD pattern (figure 1a) confirms the presence of $\gamma$-phase (Takahashi and Tadokoro 1980) in PVDF films cast at room temperature from solution at $90^{\circ} \mathrm{C}$. But small $\alpha$-phase peaks at 17.6 (100), 18.4 (020), 19.9 (110) and 26.6 (021) (Newman et al 1979) peaks are also present in XRD pattern which indicate the existence of small percentage of $\alpha$-phase along with $\gamma$-phase in PVDF film cast at room temperature from solution at $90^{\circ} \mathrm{C}$.

In figure 1(b), the maximum intensity peak is observed at 19.9 ( $2 \theta$ values) along with peaks at 17.7 and $18.4(2 \theta$ values), which belong to $\alpha$-phase. Therefore only $\alpha$ phase exists in PVDF films, cast at room temperature from solution at $50^{\circ} \mathrm{C}$.

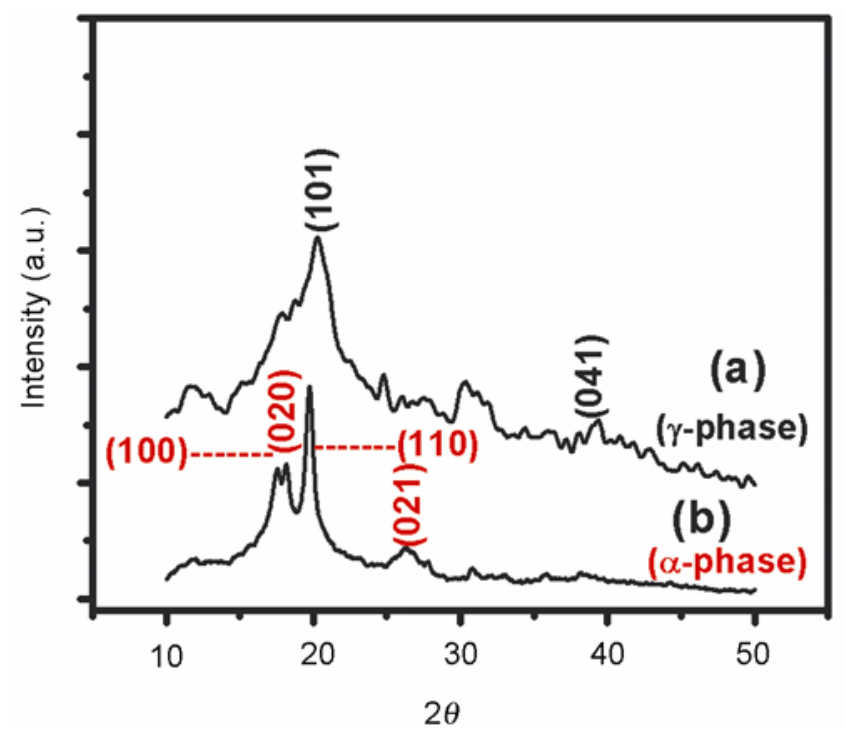

Figure 1. X-ray diffraction pattern of PVDF films. Thin film cast at room temperature from $15 \mathrm{wt} \%$ DMSO solution at (a) $90^{\circ} \mathrm{C}$ and (b) $50^{\circ} \mathrm{C}$ 
When the PVDF crystallizes from a high polar solvent, the polar groups of the solvent tend to rotate the strong dipoles of the $\mathrm{C}-\mathrm{F}$ bond in the PVDF molecular chain and reduce the energy barrier for forming the more expanded all trans conformation while solvents with a lower dipole moment always favors alternate trans and gauch conformation (Salimi and Yousefi 2004; Chen et al 2007). But same polar solvent can produce different phases depending on the preparation temperature. The existence of $\alpha, \beta$ and $\gamma$ phases in the PVDF for a particular polar solvent depends on the mobility of conformers which are mainly affected by the thermal energy (Gregorio and Cestari 1994). At $50^{\circ} \mathrm{C}$, where the viscosity of the PVDF solution is high, the thermal energy is not sufficient to rotate the $\mathrm{CF}_{2}$ group. So there is no trans-gauch conformational change. In solution the trans and gauch conformers remain as it is which results in $\alpha$-phase after cast of the PVDF films.

When the solution is prepared at $90^{\circ} \mathrm{C}$ using DMSO solvent then viscocity of the solution decreases and the thermal energy is enough to rotate $\mathrm{CF}_{2}$ dipoles resulting a cooperative motion of the neighboring $\mathrm{CF}_{2}$ groups through the large scale trans-gauch conformational change. So conformers aligned either in TTTGTTTG' ${ }^{\prime}$ or TTTT form. In our case the conformers are aligned in TTTGTTTG' sequences ( $\gamma$-phase). Therefore the solutions prepared using DMSO solvents at $90^{\circ} \mathrm{C}$ and immediately cast at room temperature produce polar PVDF films have large percentage of $\gamma$ phase. Hence solvent does not matter to produce different phases of PVDF. Same solvent can yield $\alpha, \beta$ and $\gamma$ phase.

\subsection{Effect of annealing on transformation of $\gamma$-phase $P V D F$ to $\beta$ and $\alpha$-phase PVDF}

The PVDF films with maximum percentage of $\gamma$-phase were annealed at $70,90,110,130$ and $160^{\circ} \mathrm{C}$ for $5 \mathrm{~h}$ to observe the changes in crystalline phases in PVDF films.

Figure 2 shows the XRD pattern of PVDF thin films, annealed at $70,90,110,130$ and $160^{\circ} \mathrm{C}$ for $5 \mathrm{~h}$. For comparison, the XRD pattern of PVDF film (as cast) is also shown in figure $2 \mathrm{a}$. The XRD peak position at $2 \theta=20 \cdot 3$ confirms the presence of maximum percentage of $\gamma$-phase in PVDF films without annealing. At $160^{\circ} \mathrm{C}$ for $5 \mathrm{~h}$ annealed condition, only $\alpha$-phase is present in the film (figure $2 \mathrm{f}$ ) which is confirmed from the presence of XRD peaks at $17.6(100), 18.4(020)$ and 19.9 (110). For other annealing conditions, $\beta$ - or $\gamma$-phases are present along with $\alpha$-phase. Presence of peaks at 20.7 (200) and 20.8 (110) in XRD pattern (Chen et al 2007) confirm the existence of maximum $\beta$-phase in PVDF films (figure $2 \mathrm{c}$ ) for annealing condition $90^{\circ} \mathrm{C}$ for five hours. For further confirmation of phases in PVDF films they are subjected to DSC, FTIR, and Raman characterizations.

Figure 3 shows the DSC curves (heating rate $5^{\circ} \mathrm{C} / \mathrm{min}$ ) of PVDF films annealed at different temperatures. Figure 3a shows endothermic peaks at $170^{\circ} \mathrm{C}$ for PVDF film prepared from DMSO solvent without any annealing. This endothermic peak shows the presence of $\gamma$-phase (confirmed from XRD) in the as cast PVDF films. For PVDF films annealed at $70^{\circ} \mathrm{C}$ for $5 \mathrm{~h}$, two overlapping endothermic peaks at 157 and $161^{\circ} \mathrm{C}$ appear in the DSC curve (figure 3b). According to Prest and Luca (1975) both solvent cast and the oriented $\beta$-phase can be made to melt near the $\alpha$-phase that thermal measurement alone cannot distinguish the presence of either structure (Prest and Luca 1975). The melting point of $\beta$-phase is less than the melting point of $\alpha$-phase (Gregorio Jr and Nociti 1995; Constantino et al 2005). To assign these peaks to proper phases of PVDF, first we consider the DSC curve (figure 3f) of PVDF film annealed at $160^{\circ} \mathrm{C}$ for $5 \mathrm{~h}$. At this annealed temperature only $\alpha$-phase is present in the film (confirmed from XRD and FTIR). So the endothermic peak at $161^{\circ} \mathrm{C}$ corresponds to $\alpha$-phase of PVDF. Similarly for the PVDF films annealed at $90^{\circ} \mathrm{C}$ for $5 \mathrm{~h}$, one endothermic peak is observed at $157^{\circ} \mathrm{C}$ in DSC curve (figure $3 \mathrm{c}$ ). According to XRD curve, maximum percentage of $\beta$-phase is present in the PVDF film at this annealing condition. Hence the endothermic peak at $157^{\circ} \mathrm{C}$ corresponds to $\beta$-phase present in the PVDF films. From above results it is clear that the two peaks at $157^{\circ} \mathrm{C}$ and $161^{\circ} \mathrm{C}$ present in the PVDF film at annealing condition $70^{\circ} \mathrm{C}$ for $5 \mathrm{~h}$ correspond to $\beta$ and $\alpha$-phases respectively. Therefore at this annealing condition both $\beta$ and $\alpha$-phases are present in the PVDF films. The presence of both $\beta$ and $\alpha$-phases in PVDF films (when it is annealed at $110^{\circ} \mathrm{C}$ for $5 \mathrm{~h}$ ) is also confirmed from two endothermic peaks at $157^{\circ} \mathrm{C}$ and $161^{\circ} \mathrm{C}$. When PVDF films annealed at $130^{\circ} \mathrm{C}$ for $5 \mathrm{~h}$, three broad endothermic peaks are present in the DSC thermographs (figure $3 \mathrm{e}$ ). Peak at $157^{\circ} \mathrm{C}$ gets broader and the peak at $161^{\circ} \mathrm{C}$ becomes sharper which shows the decrease in $\beta$-phase content and increase in $\alpha$-phase content. The endothermic peak at $144^{\circ} \mathrm{C}$ corresponds to relaxation of conformer. Also some kind of bond deformation may occur at this annealing condition.

In our case the melting point of different phases are low compared to reported values (Prest Jr and Luca 1978; Salimi and Yousefi 2003; Judovits 2006; Campos et al 2007). The endothermic peak positions of $\alpha, \beta$ and $\gamma$-phases depends on heating rate and also on polymerization condition of PVDF (Prest Jr and Luca 1975). The complexity of this polymeric behaviour is also reflected by its melting behavior. The melting point of the different phases in PVDF is a function of polymerization condition. The higher molecular weight polymer produced by emulsion polymerization at $350-400 \mathrm{~K}$ typically melts lower than the product of a room temperature suspension polymerization (Prest Jr and Luca 1975). In our case the molecular weight of PVDF films $\left(M_{\mathrm{w}} \approx 5,30,000\right)$, is high compared to reported values (Prest Jr and Luca 1975). Therefore the observed melting points of different phases are lower than some reported values. 

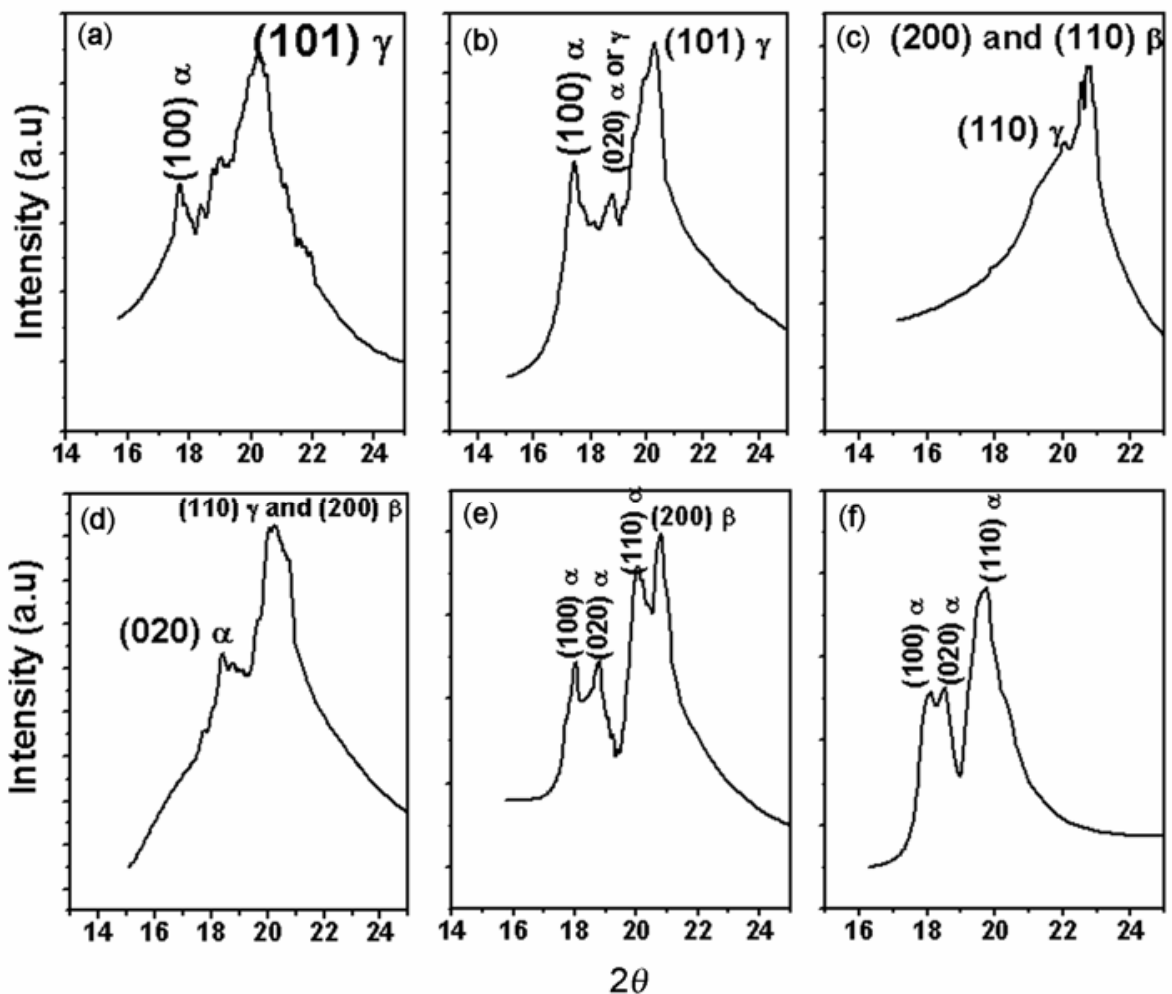

Figure 2. X-ray diffraction pattern of PVDF films (a) without annealing, (b) annealed at $70^{\circ} \mathrm{C}$ for $5 \mathrm{~h},(\mathbf{c})$ annealed at $90^{\circ} \mathrm{C}$ for $5 \mathrm{~h},(\mathbf{d})$ annealed at $110^{\circ} \mathrm{C}$ for $5 \mathrm{~h},(\mathbf{e})$ annealed at $130^{\circ} \mathrm{C}$ for $5 \mathrm{~h}$, (f) annealed at $160^{\circ} \mathrm{C}$ for $5 \mathrm{~h}$.

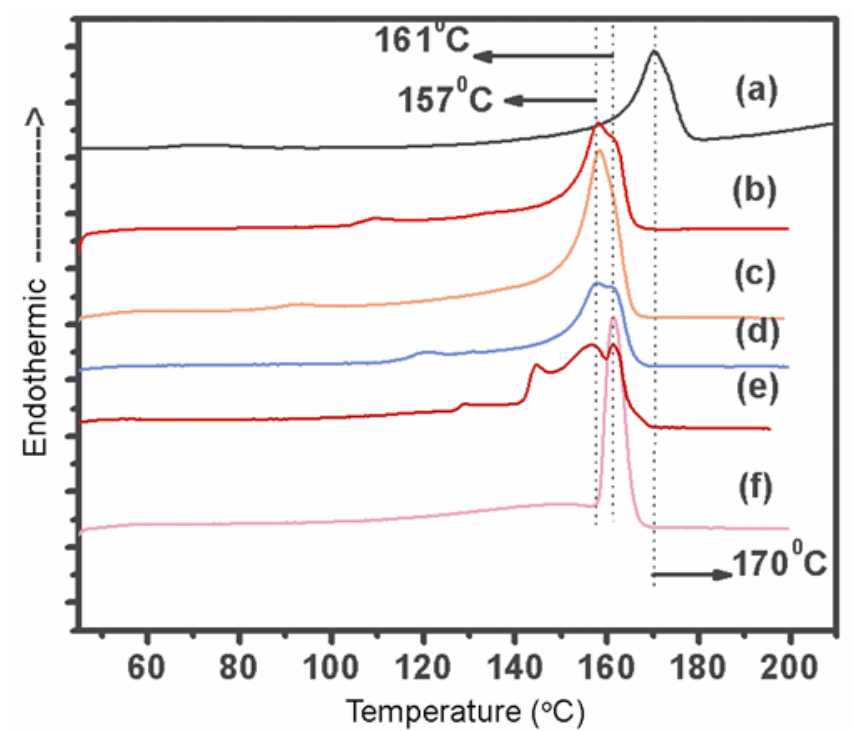

Figure 3. DSC curves of PVDF films with heating rate of $5^{\circ} \mathrm{C} / \mathrm{min}$ : (a) without annealing (b) annealed at $70^{\circ} \mathrm{C}$ for $5 \mathrm{~h},(\mathrm{c})$ annealed at $90^{\circ} \mathrm{C}$ for $5 \mathrm{~h},(\mathrm{~d})$ annealed at $110^{\circ} \mathrm{C}$ for $5 \mathrm{~h}$, (e) annealed at $130^{\circ} \mathrm{C}$ for $5 \mathrm{~h}$, (f) annealed at $160^{\circ} \mathrm{C}$ for $5 \mathrm{~h}$.

FTIR spectra of PVDF thin films in the range 400$2000 \mathrm{~cm}^{-1}$ are shown in figure 4 . According to earlier reports, the peaks at $490,530,615,766,795,974,1149$,
$1210,1383,1402,1432$ and $1455 \mathrm{~cm}^{-1}$ are used for $\alpha$-phase identification. The peaks at 511, 840 and 1275$1279 \mathrm{~cm}^{-1}$ are fingerprints of $\beta$-phase (Kobayashi et al 1975; Boccaccio et al 2002; Bormashenko et al 2004). The molecular vibration peaks of $\gamma$-phase are very close to $\beta$-phase. Therefore it is very difficult to separate $\gamma$ and $\beta$ using FTIR spectroscopy. Only two peaks 1279 and $1234 \mathrm{~cm}^{-1}$ can be unambiguously used to distinguish forms $\beta$ and $\gamma$ respectively (Boccaccio et al 2002).

Figure 4(a-f) shows the FTIR spectra of PVDF at different annealing conditions. When $\gamma$-phase PVDF films are annealed at $160^{\circ} \mathrm{C}$ for $5 \mathrm{~h}$, then absorption peaks appear at 490, 532, 615, 764, 796 and $975 \mathrm{~cm}^{-1}$ (figure 4f), indicating the complete conversion of thin film into $\alpha$ - phase. The FTIR spectrum of PVDF without annealing is shown in figure $4 a$. Figure $4(\mathrm{~b}-\mathrm{e})$ show the FTIR spectra of PVDF films, at annealing condition 70, 90, 110 and $130^{\circ} \mathrm{C}$ for $5 \mathrm{~h}$ respectively. There is not much difference in FTIR spectra of without annealing condition and annealing at $70^{\circ} \mathrm{C}$ for $5 \mathrm{~h}$. From FTIR spectra it is very difficult to distinguish the presence of $\gamma$ and $\beta$ in PVDF. Only one distinguishable small peak at $1235 \mathrm{~cm}^{-1}$ is present in FTIR spectrum of without annealed PVDF (figure 4a). But from other characterizations it is clear that the maximum percentage of $\gamma$-phase is present in without annealed PVDF film. The maximum increase of $\beta$-phase is observed when thin film of PVDF is annealed at $90^{\circ} \mathrm{C}$ 
for $5 \mathrm{~h}$ (figure $3 \mathrm{c}$ ). The increase in intensities of the peaks at 511,840 and $1276 \mathrm{~cm}^{-1}$ indicates the increase of $\beta$ phase in PVDF thin films compared to other annealing conditions.

Figure 5 shows the Raman spectra of PVDF films at different annealing temperatures for $5 \mathrm{~h}$. In figure $5 \mathrm{f}$ the Raman spectrum is dominated by characteristic bands at 613 and $796 \mathrm{~cm}^{-1}$ which confirm the complete conversion of PVDF into $\alpha$-phase at annealing condition $160^{\circ} \mathrm{C}$ for $5 \mathrm{~h}$ (Boccaccio et al 2002). At all other annealing temperatures including without annealing condition, the Raman spectra are dominated by a band at $839 \mathrm{~cm}^{-1}$

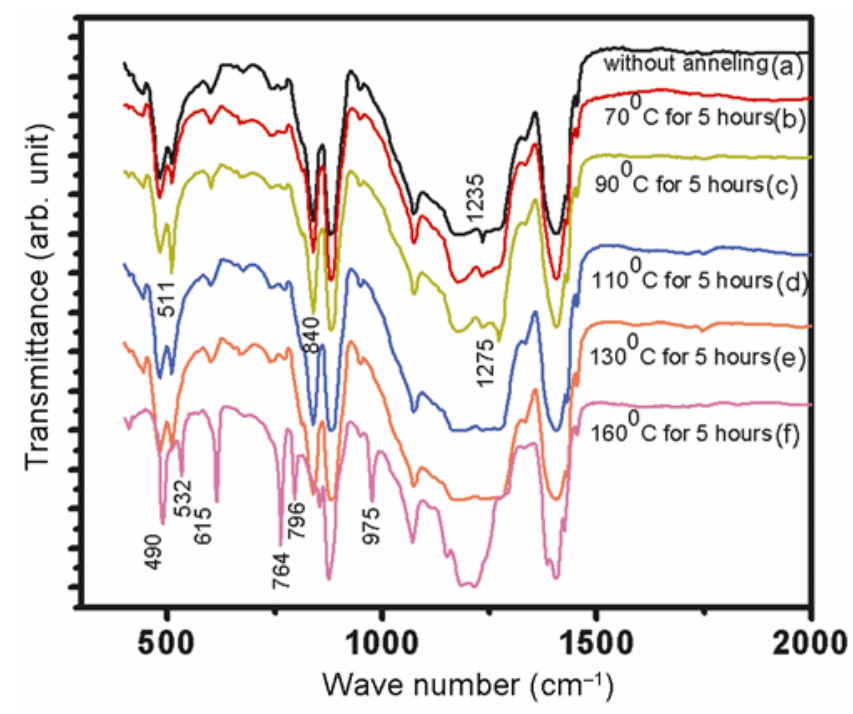

Figure 4. FTIR spectra of PVDF films.

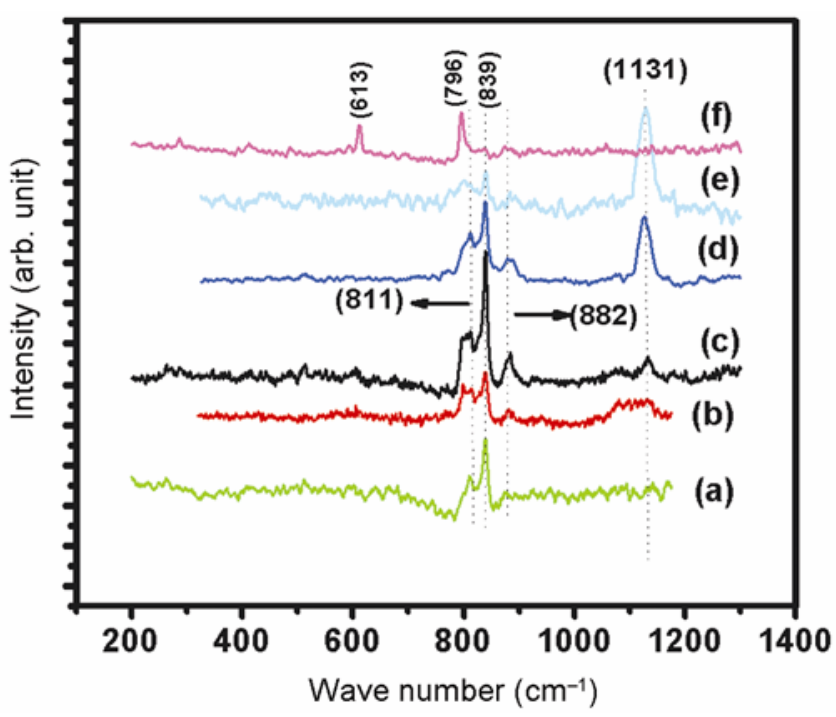

Figure 5. Raman spectra of PVDF films: (a) without annealing, (b) annealed at $70^{\circ} \mathrm{C}$ for $5 \mathrm{~h}$, (c) annealed at $90^{\circ} \mathrm{C}$ for $5 \mathrm{~h}$, (d) annealed at $110^{\circ} \mathrm{C}$ for $5 \mathrm{~h}$, (e) annealed at $130^{\circ} \mathrm{C}$ for $5 \mathrm{~h}$, (f) annealed at $160^{\circ} \mathrm{C}$ for $5 \mathrm{~h}$. (figure $5 \mathrm{a}-\mathrm{e}$ ). This band is common to both $\beta$ and $\gamma$-phases of PVDF but very strong only in the first case. So the peak at $839 \mathrm{~cm}^{-1}$ confirms the presence of either $\gamma$, $\beta$ or both phases (ferroelectric phase) in PVDF film. The high intensity peak at $839 \mathrm{~cm}^{-1}$ confirms the high percentage $\beta$-phase at annealing condition $90^{\circ} \mathrm{C}$ for $5 \mathrm{~h}$ (Boccaccio et al 2002). The Raman bands at $811 \mathrm{~cm}^{-1}$ in as cast PVDF films, correspond to $\gamma$ phase. From Raman spectra it is clear that the PVDF film without annealing contains mainly $\gamma$-phase. The percentage of $\gamma$-phase decreases as annealing temperature increases to $90^{\circ} \mathrm{C}$. At this annealing temperature the PVDF mainly consists of $\beta$-phase along with small percentage of $\alpha$ conformers. After $90^{\circ} \mathrm{C}$ the percentage of $\alpha$-phase increases in PVDF film and the film is completely converted to $\alpha$-phase at $160^{\circ} \mathrm{C}$.

The broad Raman peak at $882 \mathrm{~cm}^{-1}$ represents the combination of all three phases (Bormashenko et al 2004). At annealing temperature 110 and $130^{\circ} \mathrm{C}$, the extra peak appearing at $1131 \mathrm{~cm}^{-1}$ may be assigned to combination of $\alpha$ - and $\beta$-phases present in PVDF films (Constantino et al 2005).

The maximum percentage of $\beta$-phase PVDF is obtained by annealing the PVDF film (cast using DMSO solvent) at $90^{\circ} \mathrm{C}$ for $5 \mathrm{~h}$. As per literature, for an applied field of $1200 \mathrm{kV} / \mathrm{cm}$, the remnant polarization is $5 \mu \mathrm{C} /$ $\mathrm{cm}^{2}$ at $0.001 \mathrm{~Hz}$. But at an applied field of $400 \mathrm{kV} / \mathrm{cm}$ the $\beta$-PVDF shows polarization of $0.2 \mu \mathrm{C} / \mathrm{cm}^{2}$ at $0.001 \mathrm{~Hz}$ (Furukawa et al 1980). The figure 6a shows the hysteresis loops of unpoled $\beta$-phase PVDF for different frequencies at constant field $400 \mathrm{kV} / \mathrm{cm}$. When frequency of applied field $400 \mathrm{kV} / \mathrm{cm}$ decreases from $50 \mathrm{~Hz}$ to $1 \mathrm{~Hz}$ the ferroelectric polarization increases from $0.045 \mu \mathrm{C} / \mathrm{cm}^{2}$ to $0.186 \mu \mathrm{C} / \mathrm{cm}^{2}$. Well saturated ferroelectric loop appears with remnant polarization $4.8 \mu \mathrm{C} / \mathrm{cm}^{2}$ obtained at an applied field of $1400 \mathrm{kV} / \mathrm{cm}$ (figure $6 \mathrm{~b}$ ).

The temperature and time of crystallization determine the presence of predominant phases in PVDF. Maximum percentage of $\gamma$-phase is present in initial PVDF film cast at $90^{\circ} \mathrm{C}$. When thin films are annealed at $70^{\circ} \mathrm{C}$, the thermal energy indeed changes the phases present in PVDF but the temperature is not sufficient enough to completely destroy the crystalline order present in PVDF film. There is rotation of dipole groups around chain axis to change the conformers. So the TTTGTTTG' sequence present in PVDF chain try to acquire TTTT sequence. When PVDF films are annealed at $90^{\circ} \mathrm{C}$ for $5 \mathrm{~h}$ the viscocity of material decreases which in turn increases chain mobilty and thermal energy is enough to reorganize the structure of conformers. So the TTTGTTTG' sequence in PVDF chain completely converts to TTTT sequence i.e. $\gamma$-phase to $\beta$ phase. At this temperature crystallization rate of $\beta$ phase is also higher than among other phases. Therefore at annealing condition $90^{\circ} \mathrm{C}$ for $5 \mathrm{~h}$, the characterizations show presence of maximum percentage of $\beta$-phase in PVDF film. 

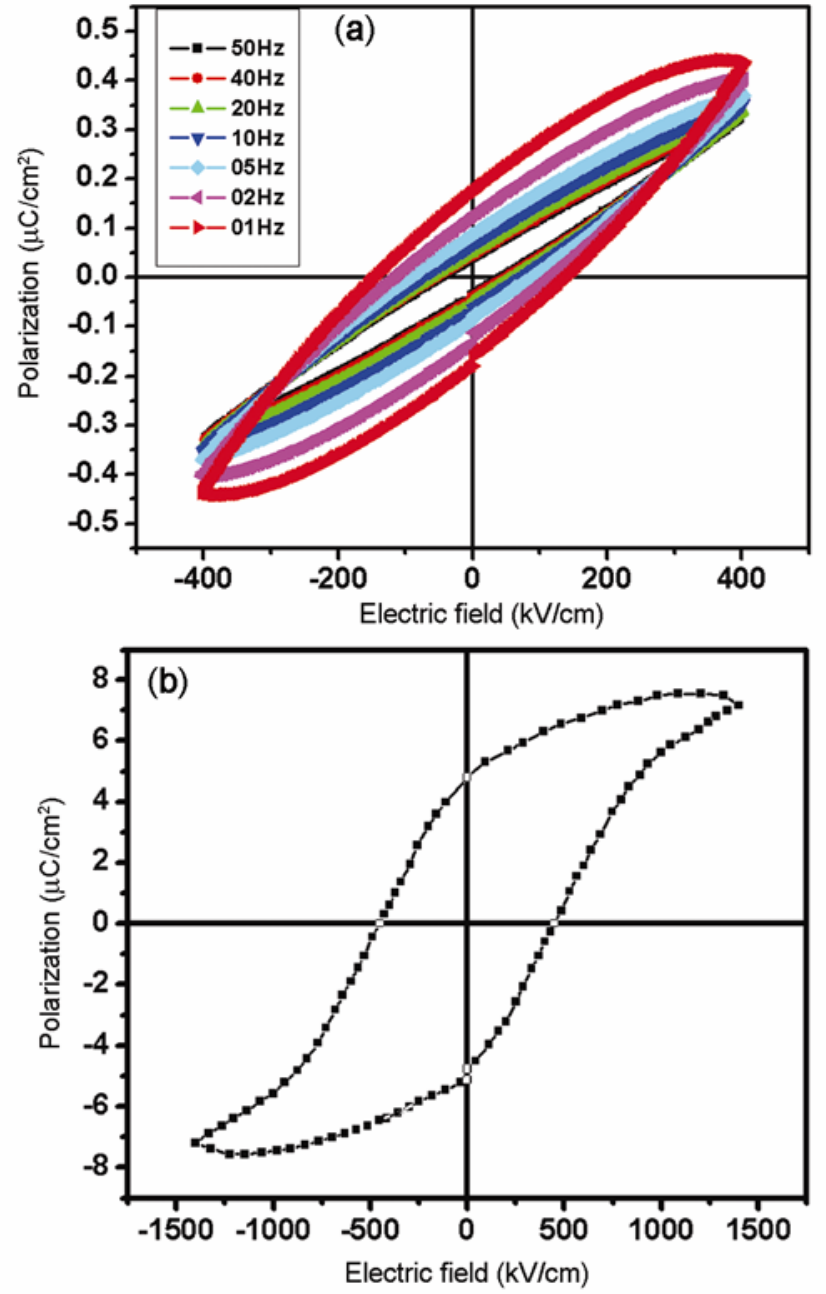

Figure 6. (a) Hysteresis loops of unpoled transparent PVDF films (cast using DMSO solution and annealed at $90^{\circ} \mathrm{C}$ for $5 \mathrm{~h}$ ) at an applied field $400 \mathrm{kV} / \mathrm{cm}$ at different frequencies. (b) Hysteresis loop of $\beta$-phase PVDF film at an applied field $1400 \mathrm{kV} / \mathrm{cm}$ at $1 \mathrm{~Hz}$

As the annealing temperature increases above $110^{\circ} \mathrm{C}$, the viscocity of PVDF decreases further to allow the active chain motion and chain reorientation in the crystalline region through the trans-gauche conformational exchange (Gregorio Jr and Cestari 1995). Therefore due to deformation in crystalline region and reorientation of chains, the more stable $\alpha$ phase reappears in the PVDF films at high temperature annealing conditions. Hence at 110 and $130^{\circ} \mathrm{C}$ there is increase in percentage of $\alpha$-phase increase in PVDF film. Above $160^{\circ} \mathrm{C}$ PVDF completely gets converted to $\alpha$-phase.

\section{Conclusions}

In this report it is observed that the same polar solvent can yield all the three phases of PVDF. By changing the solution temperature, different phases of PVDF can be obtained using polar DMSO solvent. The annealing conditions decide the presence of different phases and conversion of one phase to other phase of PVDF. The $\beta$-phase which is important for ferroelectric application is obtained using polar solvent and by suitable annealing. Maximum $\beta$-phase exist in the films when PVDF films are annealed at $90^{\circ} \mathrm{C}$ for $5 \mathrm{~h}$. The $\gamma$-phase completely converts to $\alpha$-phase at annealing temperature $160^{\circ} \mathrm{C}$ for $5 \mathrm{~h}$. The phase conversion at different annealing condition has been confirmed from XRD, FTIR, DSC, and Raman studies. Polarization measurement of PVDF film, having high $\beta$-phase content shows a remnant polarization of $4.9 \mu \mathrm{C} / \mathrm{cm}^{2}$ at $1400 \mathrm{kV} / \mathrm{cm}$ at $1 \mathrm{~Hz}$.

\section{Acknowledgement}

We thank Dr V G Sathe, Dr S M Gupta, Mr Rahul Vaish and $\mathrm{Mr}$ Prem Kumar for their support in characterizations.

\section{References}

Boccaccio T, Bottino, Capannelli G and Piaggio P 2002 J. Membrane Sci. 210315

Bormashenko Y, Pogreb R, Stanevsky O and Bormashenko E 2004 Polym. Testing 23791

Buonomenna M G, Macchi P, Davoli M and Drioli E 2007 Euro. Polym. J. 431557

Campos J S D C, Riberio A A and Cardoso C X 2007 Mat. Sci Eng. B136 123

Chen S, Yao K, Tay F E H and Liow C L 2007 J. Appl. Phys. 102104108

Constantino C J L, Job A E, Simoes R D, Giacometti J A, Zucolotto V, Oliveira Jr O N, Gozzi G and Chinaglia D L 2005 Appl. Spectrosc. 59275

Cortili G and Zerbi G 1967 Spectrochim Acta Part A: Mol. Spectrosc. 23285

Dasgupta D K and Doughty K 1978 J. Appl. Phys. 494601

Davis G T, McKinney J E, Broadhurst M G and Roth S C 1978 J. Appl. Phys. 494998

Furukawa T, Date M and Fukada E 1980 J. Appl. Phys. 51 1135

Gal'Perin Ye L, Kosmynim B P and Bychkov R A 1970 Vysokomol Soe-din B 12555

Gregorio Jr R and Cestari M 1994 J. Poly. Sci.: Part B: Poly. Phys. 32859

Gregorio Jr R and Nociti N C P D S 1995 J. Phys. D.: Appl. Phys. 28432

Hasegawa R, Kobayashi M and Tadokoro H 1972a Polym. J. 3 591

Hasegawa R, Takahashi Y, Chatani Y and Tadokoro H 1972b Polymer 3600

He X and Yao K 2006 Appl. Phys. Lett. 89112909

Judovits L 2006 Thermochim. Acta 44292

Kobayashi M, Tashiro K and Tadokoro H 1975 Macromolecules 8158

Lando J B, Olf H G and Peterlin A 1966 J. Polym. Sci. Part A-1: Polym. Chem. 4941 
Mohammadi B, Yousefi A and Bellah S M 2007 Polym. Testing 2642

Newman B A, Yoon C H and Pae K D 1979 J. Appl. Phys. 50 6095

Okuda K, Yoshida T, Sugita M and Asahina M 1967 J. Polym. Sci. Part B: Polym. Letts. 5465

Park Y J, Kang Y S and Park C 2005 Euro. Polym. J. 41 1002

Prest Jr W M and Luca D J 1975 J. Appl. Phys. 46 4136

Prest Jr W M and Luca D J 1978 J. Appl. Phys. 495042
Sajkiewicz P, Wasiak A and Goclowski Z 1999 Euro. Polym. J. 35423

Salimi A and Yousefi A A 2004 J. Polym. Sci., Part B: Polym. Phys. 423487

Salimi A and Yousefi A A 2003 Polym. Testing 22699

Takahashi Y and Tadokoro A 1980 Macromolecules 13 1318

Weinhold S, Litt M H and Lando J B 1980 Macromolecules 13 1178

Welch G J and Miller R L 1976 J. Polym. Sci.: Polym. Phys. Edition 141683 